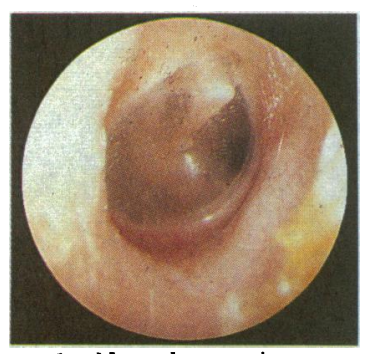

FIG 1-Normal tympanic membrane

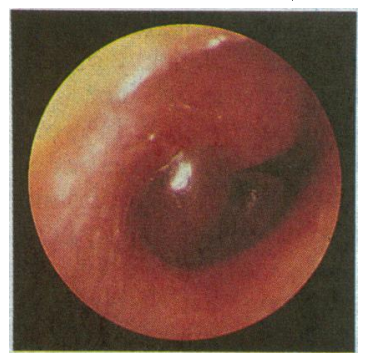

FIG 2-Bulging red eardrum:

antibiotic indicated

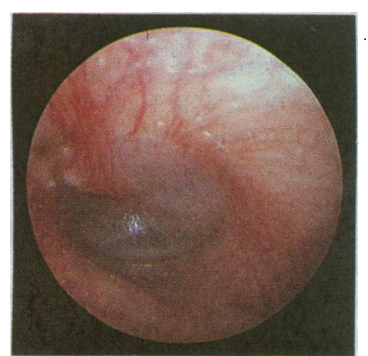

FIG 3-Leash of blood vessels on eardrum: use of antibiotics doubtful likely to develop recurrent problems and in which children antibiotic treatment will reduce recurrences of middle ear infection.

There is little evidence to show that decongestant and antihistamine mixtures relieve the associated symptoms of acute otitis media or improve eustachian tube dysfunction. ${ }^{1314}$ In addition, side effects such as irritability, nightmares, and visual hallucinations have been reported. ${ }^{15}{ }^{16}$ Despite this, many ear, nose, and throat surgeons still advocate their use.

Follow up at six to eight weeks after an acute episode is advisable in young children. When attacks have recurred subsequent review depends on individual circumstances but has to include an assessment of hearing as well as examination of the eardrum. Most children with episodic middle ear infections will not develop serious problems, and the trend in some quarters towards increasing referrals for specialist opinion has to be questioned. A spiral of referral followed by unproved surgical intervention is not always in the best interests of many children with self limiting problems. ${ }^{17}$

\section{Clinical judgment}

The term acute otitis media is often a label to justify the use of antibiotics rather than a true reflection of the underlying disease. This is understandable given the nature of primary medical care, where it is false to assume that general practitioners have access to full knowledge of probabilities, events, and outcomes in caring for the wide range of undifferentiated problems presented to them. Merely condemning general practitioners for apparent overprescribing is insufficient without an understanding of the close interplay of physical, psychological, and social features of children's presenting problems. Before taking decisions on the use of drugs parental expectations have to be explored with the reminder that "diseases fall into new and more relevant groups when illness is seen in its family context."

Research on disorders of the middle ear has been largely confined to hospitals, and a better understanding of the natural course of otitis media can be achieved only by conducting more of the original work in general practice. The traditional model of biomedical research does not always fit easily into the primary care setting, where critical inquiry has to combine investigation of presenting symptoms and signs in conjunction with analysis of decision making by general practitioners. This research has also to include methods to promote improvements in the delivery of primary care by general practitioners, health visitors, and practice nurses. Shared policies in group practice are the exception rather than the norm. It is not a question of what is right or wrong but more a matter of ensuring that the reasons for decisions on management are both understood and thought through.

The photographs are reproduced by permission of MTP Press, Lancaster, from Colour Atlas of Mouth, Throat and Ear Disorders by J Bain, P Carter, and R Morton (1985).

1 Medical Research Council. Acute otitis media in general practice. Lancet 1957;ii:510-4.

2 Lowe JF, Bamforth JS, Pracy R. Acute otitis media: one year in general practice. Lancet $;$ ii: 1129-32.

3 Howie VM, Ploussard JG, Sloyer J. The otitis prone condition. Am f Dis Child 1975;129:676.

4 Paradise JL. Otitis media in infants and children. Pediatrics 1980;65:917-43. 5 Fry J. Common diseases: their nature, incidence and care. 3rd ed. Lancaster: MTP Press, 1983.

6 Halsted C, Lepon ML, Balassanian N, et al. Otitis media: clinical observations, microbiology and evaluation of therapy. Am $\mathcal{J}$ Dis Child 1968;115: $542-51$.

7 Bluestone $\mathrm{CD}$. Recent advances in the pathogenesis, diagnosis and management of otitis media. Pediatr Clin North Am 1981;28:727-55.

8 Pitts J. Shared decision making in the informed treatment of acute otitis media. Practitioner 1987;231:1232-3.

9 Bain DJG, Murphy E, Ross F. Acute otitis media: clinical course among children who received a short course of high dose antibiotic. $\mathrm{Br} \mathrm{Med} \mathcal{F}$ 1985;291:1243-6.

10 Jones RH, Bain DJG. Three day and seven day treatment in acute otitis media: a double blind antibiotic trial. $\mathcal{F} R$ Coll Gen Pract 1986;36:356-8.

11 Van Buchem FL, Peeters MF Van't Hof MA. Acute otitis media: a new treatment strategy. Br Med F 1985;290:1033-7.

12 Mygind N, Meistrup-Larsen KI, Thomsen J, et al. Penicillin in acute otitis media: a double-blind placebo controlled trial. Clin Otolaryngol 1981:6:5-13.

3 Bain DJG. Can the clinical course of acute otitis media be modi decongestant or antihistamine treatment? Br Med $\mathcal{F}$ 1983;287:654-6.

14 Cantekin EI, Mandell EM, Bluestone CD, et al. Lack of efficacy of a decongestant-antihistamine combination for otitis media in children. $N$ Engl decongestant-antihistaminec

15 Lewith GT, Davidson F. Dystonic reactions to Dimotapp elixir. $\mathcal{F} R$ Coll Gen Pract 1981;31:241.

16 Sankey RJ, Nunn AJ, Sills JA. Visual hallucinations in children receiving decongestants. Br Med F 1984;288:1369.

7 Black NA. Glue ear: the new dyslexia. BrMed $\mathcal{F}$ 1985;290:1963-5.

18 Miller FJW, Court SDM, Walton WS, Knox EG. Growing up in Newcastle upon Tyne 1960. Oxford: Oxford University Press.

\section{ANY QUESTIONS}

\section{What is the most appropriate site for taking arterial blood for gas sampling?}

In most cases blood samples from anywhere in the systemic arterial tree will yield comparable results on blood gas analysis. The choice of the site for sampling is therefore governed by other factors, not least of which are the skill and experience of the doctor concerned. When sampling with a needle it is logical to use an artery that is superficial, easily palpated (and easily compressed after puncture), and relatively immobile. A paucity of veins in the vicinity reduces the likelihood of misleading results from venous sampling, and the absence of any large nerves reduces the possibility of nerve injury. It is also wise to select an artery with a good collateral flow to minimise the small risk of ischaemic complications.

The site which most closely meets these requirements is the radial artery at the wrist. It is preferable to select the non-dominant hand, particularly in patients who will be using the arm soon afterwards. Only in the rare circumstances of pulmonary hypertension with right to left shunting through a patent ductus arteriosus may the composition of radial arterial blood differ between the two sides. This discrepancy occurs if a proportion of the shunted, unsaturated blood enters the left subclavian artery. This is likely to be encountered only in children, particularly in the neonatal period while the circulation remains transitional. Under such circumstances blood sampled anywhere beyond the aortic arch will always differ from that taken from the right radial artery. The latter, being preductal, will reflect the composition of blood perfusing the head and neck, while a postductal sample will reflect that of blood perfusing the rest of the body.
Puncture of the radial artery may produce pain for some hours afterwards even if local anaesthetic and a small needle are used. ${ }^{1}$ It has been suggested anecdotally that puncture of the brachial artery may be less painful, though there is no good evidence for this. While an Allen test is frequently performed to confirm an adequate ulnar collateral flow, the result does not necessarily predict ischaemic damage. ${ }^{2}$ If for any reason radial arterial sampling is impracticable the brachial, femoral, or dorsalis pedis arteries may be used.

If frequent repeated samples are necessary or if arterial pressure requires constant monitoring an indwelling cannula may be indicated. In general, the same considerations will apply when selecting a suitable site for cannulation, though in some circumstances there may be reasons for choosing a larger artery. ${ }^{3}-\mathrm{M}$ S NIELSEN, consultant anaesthetist, Southampton

1 Clark GS, Latto IP, Davies JM. Symptoms following radial artery puncture. Anaesthesia 1982;37:78-9.

2 Wilkins RG. Radial artery cannulation and ischaemic damage: a review. Anaesthesia 1985;40: 896-9.

Gurman GM, Kriemerman S. Cannulation of big arteries in critically ill patients. Crit Care Med $1985 ; 13: 217-20$

\section{Correction}

Ischaemic heart disease

In the Any Question answered by Dr G R. Thompson about an 8 year old child with a family history of ischaemic heart disease ( 24 March, $p 806$ ) the penultimate sentence should read: "I would not recommend using a hydroxy methyl glutaryl coenzyme A reductase inhibitor in a young girl but this might be considered in later life." We apologise for this editorial error. 